\title{
Studying the Effect of Reconstruction and Renovation of Cultural Heritage in Enabling the Old Texture Residents: Case Study of Zeinabieh in Isfahan, Iran
}

\author{
Farzad Momeni ${ }^{1} \&$ Mehdi Momeni $^{2}$ \\ ${ }^{1}$ Department of Urban Planning, Naein Branch, Islamic Azad University, Naein, Isfahan, Iran \\ ${ }^{2}$ Department of Geography \& Urban Planning, Najafabad Branch, Islamic Azad University, Najafabad, Isfahan, \\ Iran \\ Correspondence: Mehdi Momeni, Department of Geography \& Urban Planning, Najafabad Branch, Islamic Azad \\ University, Najafabad, Isfahan, Iran. E-mail: momeni100@gmail.com
}

Received: July 6, 2015 Accepted: July 14, 2015 Online Published: September 27, 2015

doi:10.5539/jsd.v8n8p234

URL: http://dx.doi.org/10.5539/jsd.v8n8p234

\begin{abstract}
Isfahan is the cultural capital of Iran. It has so many valuable historical places of which Zeinabieh is one of the most famous places which is located in district 14. Zeinabieh, as a cultural heritage, is regarded as the potential and motivation for the development of this district. The people's participation in this district can be used in order to not only change the texture and cultural situation of this neighborhood, but also makes people to be more capable. Therefore, present study is done aiming at providing the infrastructure to sustainably and comprehensively improve the current condition to optimize the inefficient texture; making appropriate conditions to serve the citizens and pilgrims; preparing proper context for the people to fully take part in the process of renovating the old texture and improving the quality of the texture. The methodology of the study is applicable by purpose and descriptive-analytic by nature. The collected data have been descriptively analyzed using SPSS. The findings show that there is no significant correlation between management issues and renovation regarding the cultural empowerment, but there is a significant correlation among economic empowerment, management empowerment and textural empowerment and the effects will be indirect. The social empowerment is directly correlated which indicates the effect of urban management on making social capital in the city projects. So, the designing Zeinabieh districts as a main potential and people's attraction center can lead to improvement of serving quality, texture quality, people's life style and their participation.
\end{abstract}

Keywords: empowerment, renovation and reconstruction, cultural heritage, Zeinabieh of Isfahan

\section{Introduction}

Regarding the geographical situation of this city in the center of Iran, Isfahan has some specific regional features. The city used to be the capital of Iran about 400 years ago in Safavid era and this fact caused the city to be culturally and religiously flourished and the city is called the culture and art capital of Iran. Zeinabieh district is located in the north of Isfahan and used to be a suburb area but now is a part of city due to city development. The municipality of 14th district was established in 2009 for Zeinabieh district, but the old texture in this area, unusual and non-standard houses, too small and narrow alleys and streets which are in contrast with urbanization principles have made fulfilling people's needs impossible in this district. Furthermore, the people living in the area, with different cultures, economic situation and poverty have made it impossible to intervene in this area with ordinary methods. The existence of holy shrine of Zeinabieh (the daughter of one of Imams) as a development potential of this district and attraction of people's participation and also the existing rule about the dominating rules on the old and inefficient urban texture and existing the informal residential places in this district can be used in a way that beside cultural and textural changes in this district like other districts of Isfahan, it will benefit from urban identity and high class nationally and internationally and will cause this district to be more empowered. This fact will necessitate following the specific principles of urbanizations and urban designations beside applicable strategic management in a process-oriented frame. This research was done after asking if the renovation of Zeinabieh can cause the empowerment of the residents of this district or not? Whether the current condition can fulfill the needs of Zeinabieh pilgrims or not, is another question? Does the current 
condition of lands application can texturally and functionally meet the needs of residents and pilgrims? The present study has been done assuming that there is a significant correlation between the renovations of Zeinabieh and empowering the residents of this district.

\section{Literature Review}

One of oldest theories regarding the subject of this research, the formation and development of old texture, is the Plato's theory. He believes that as the cities grow and develop physically, there will appear some problems in different sections of the city. Therefore, as the cities grow and develop physically, the proper situation of living must be provided and the mental needs of the residents should be met (Plato, 1969).

Rahnama (1996) did a research under the title of "the Renovation of Old Texture and Urban Development" and started to recognize the formation elements of old texture and analyze the existing relationship between them and determine their importance degree in the process of recording the correlation of old neighborhoods of city center especially preventing the wearing out of Mashhad city center using the scientific techniques.

Empowering the old texture was followed in all the aspects of economic, textural, social and cultural in the frames of comprehensive methods of city repair to 1990s. Service presentation and creating social participation was also considered for the deprived groups of the society (Abers, 2001).

Following the inclinations toward repairing the old texture in the west, the urban changes and the changing path was evolved in a way that we witness that the qualitative functional-textural issues are in focus after the passage of emergency actions period. The partnership, companionship, close relation and peaceful conversation of styles and cultures are started and the artistic cultural aspects are dominated in the creation of dynamic and attractive environment of the city (Habibi \& Maghsudi, 2007). Following is a list of the works done on the same topic as this research.

The renovation operations of the urban texture was first become important in the Renaissance period with decorating and designing the city and appropriating the city environments and to achieve this some interventions was done in the present paths of the city. The small houses and apartments next to the street are formally changed. In some case, the destruction of some parts of the old texture was the last solution to widen the square and make new urban spaces (Falamaki, 2004). From the second half of the nineteenth century onward, the interventions in the texture of the city have been done in two different ways. On one hand, the new laws were codified in England, afterward some of the problems of populated centers of the old industrial cities are gradually evolved and on the other hand, the problems resulted from unorganized situations are greatly affected through operative facilities and unprecedented decisions made by Baron Haussmann, the mayor of Paris (Ezhdari Tashriq, 2004).

Bouchani (2004) has written a paper titled "Renovation and Reconstruction of the Old districts of the City" and tried to picture an example of the renovations done in the city and he finally concluded that most of the renovated districts are located in the sections which were economically beneficial for the municipality.

The first legal measure in renovating and beautifying the cities in Iran were taken in 1941 by approving the law of repairing and developing the paths. The renovation and reconstruction processes were stopped in Iran from 1941 to 1966 . Through amending the municipalities' law and annexing some bills to this law, the new era of reconstruction and renovation of different cities was started, but the importance of renovating the old texture caused the governors to include this issue in the law of fourth development program in the future plans of Islamic Republic of Iran. This program was started in 2005 and continued to 2009. Some items are stated about the old texture and also the resources, budgets and special prominences to do the renovations were determined (Andalib, 2007).

Writing a paper titled "Social Engineering and the Role of People's Participation in Realizing the Renovation in Urban Old Texture", Adib Zade et al. (2011) examined the role of participation in social engineering and people's participation. They stated the advantages of enhancing peoples' participation resulted from the social engineering.

Asadian and Sayahi (2011) studied the role and amount of people's participation in renovation and reformation of the old texture and determined the wearing out indexes. They published their paper under the title of "the Role of Participation Pattern in Reformation and Renovation of Old Texture Using the Geographical Data and case Study of Ameri Neighborhood in Ahvaz".

Evaluating the participation pattern in Sirous neighborhood of Teheran and providing necessary setting to practice the participation in this district, Akbar Pour Sareskanroud et al. (2011) did a study under the title of "Evaluation of Participation in Reformation and Renovation of Old Texture of Sirous neighborhood of Teheran". 
They finally announce the results of lack of participation in both provision and implementation of the program (Akbar Pour et al., 2011).

Writing a paper on "Participatory of Urban Development and the People's Place in Urban Planning", Khademolhoseini and Arefi Pour (2012) examined the people's role in urban planning of the sixth district of Isfahan. It can be concluded that the citizens took part in the renovation and reformation of the district through forming coherent and disciplined organizations and also participated in the improvement of city management. The authorities used people's ideas about the city programming and informed the citizens about the plans of the city.

Ziari et al. (2013) architecturally studied the relationship between the city ruling criteria and citizens' participation and published their paper under the title of "Measuring the People's Participation in Urban Management according to Ruling Pattern, Case study: Yasouj".

Movahed et al. (2013) have a paper titled "the Role of People-oriented organization for Participation in the renovation of Old Texture" aiming at evaluating the role of these organizations in renovation and reformation of old texture. The findings demonstrate that reinforcing the cultural and ethnic values result in the fortification of people's participation and activating these organizations.

\section{Methodology}

The methodology of the study is applicable by purpose and descriptive-analytic by nature. The data have been analyzed qualitatively, quantitatively and descriptively. The data have been collected through library and field methods. To achieve the demands and needs of people and their environment and to realize the goals of the present research, direct and indirect interviews, questionnaires and special documents to clear the necessities of the problem were arranged. The population of the study is some hectares of the lands located in Zeinabieh and Arzanan districts and the best sampling method for this study is the "relative stratified random method". The sampling was done in a way that the ratio of one out of twenty was selected in lieu of the population of each family to the separation of the located blocks in the area. The selected fraction of $1 / 20$ from each block was done randomly and it was done before according to the number of the houses and the entered codes in GIS which is the same for each family. In the other word, the SRE method would be applied in the separated population. The statistical methods (descriptive-analytic) and the analytic statistical software (SPSS) were used to analyze, approve or reject the hypothesis of the research.

\section{Data Analysis}

\subsection{Calculating the Sample Size}

The whole residents of the district with the population of 4630 people that form the population of the research are used to approve or reject the related hypothesis. The selected sample size was calculated using the Cochran formula and random sampling. The value of it was calculated according to the formula below:

$$
n=\frac{\frac{t^{r} p q}{d^{r}}}{1+\frac{1}{N}\left(\frac{t^{r} p q}{d^{r}}-1\right)}
$$

$\mathrm{N}=$ Sample $=350$

$\mathrm{N}=$ population that is 4630 people

$\mathrm{T}=$ the confidence coefficient of $95 \%$ that equals to 1,96 (the value of the variable in normal distribution table)

$\mathrm{D}=$ the confidence distance that equals to 0.05

To measure the reliability of the questionnaire, Cronbach Alfa in SPSS was used. The obtained Alfa coefficient was 0.77 . Therefore, the questionnaire is reliable enough.

Studying the design and renovation of old and problematic texture, three factors of the existing facilities in the neighborhood, urban management and participation of the private section were determined. Each of these factors has various indexes which are regarded as extra important using the surveyed questionnaire. The Tables below demonstrate the empowerment factors in point of view of participants according to Likert range. 
Table 1. Studying the empowerment factors

\begin{tabular}{ccccc}
\hline \multicolumn{5}{c}{ Statistics } \\
\hline & $\begin{array}{c}\text { Existing Facilities in the } \\
\text { Neighborhood }\end{array}$ & $\begin{array}{c}\text { Urban } \\
\text { Management }\end{array}$ & $\begin{array}{c}\text { Participation of Private } \\
\text { Section }\end{array}$ \\
\hline \multirow{2}{*}{ N } & Valid & 350 & 350 & 350 \\
& Missing & 0 & 0 & 0 \\
& Mean & 1.66 & 2.75 & 2.79 \\
& Sum & 581 & 961 & 977 \\
\hline
\end{tabular}

Table 2. The existing facilities in the neighborhood

\begin{tabular}{llllll}
\hline \multicolumn{5}{c}{ Frequency Table } \\
\hline Valid & Frequency & \multicolumn{1}{c}{ Percent } & Valid Percent & Cumulative Percent \\
& Very Low & 183 & 52.3 & 52.3 & 52.3 \\
& Low & 112 & 32.0 & 32.0 & 32.0 \\
& Somewhat & 46 & 13.1 & 13.1 & 97.4 \\
& Much & 9 & 2.6 & 2.6 & 100.0 \\
& Total & 350 & 100.0 & 100.0 & \\
\hline
\end{tabular}

Table 3. Urban management

\begin{tabular}{cccccc}
\hline \multicolumn{5}{c}{ Urban management } \\
\hline \multirow{4}{*}{ Valid } & Frequency & Percent & Valid Percent & Cumulative Percent \\
& Very Low & 52 & 14.9 & 14.9 & 14.9 \\
& Low & 85 & 24.3 & 24.3 & 39.1 \\
& Somewhat & 132 & 37.7 & 37.7 & 76.9 \\
& Much & 62 & 17.7 & 17.7 & 94.6 \\
& Very Much & 19 & 5.4 & 5.4 & 100.0 \\
& Total & 350 & 350 & 100.0 & \\
\hline
\end{tabular}

Table 4. The participation of private section

\begin{tabular}{cccccc}
\hline \multicolumn{5}{c}{ Participation of Private Section } \\
\hline Valid & Frequency & Percent & Valid Percent & Cumulative Percent \\
& Very Low & 68 & 19.4 & 19.4 & 19.4 \\
& Low & 65 & 18.6 & 18.6 & 38.0 \\
& Somewhat & 119 & 34.0 & 34.0 & 72.0 \\
& Much & 68 & 19.4 & 19.4 & 91.4 \\
& Very Much & 30 & 8.6 & 8.6 & 100.0 \\
& Total & 350 & 100.0 & 100.0 & \\
\hline
\end{tabular}


Table 5. The aspects of empowerment

\begin{tabular}{ccccccc}
\hline \multicolumn{7}{c}{ Aspects of Empowerment } \\
\hline & & $\begin{array}{c}\text { Economic } \\
\text { Empowerment }\end{array}$ & $\begin{array}{c}\text { Social } \\
\text { Empowerment }\end{array}$ & $\begin{array}{c}\text { Management } \\
\text { Empowerment }\end{array}$ & $\begin{array}{c}\text { Cultural } \\
\text { Empowerment }\end{array}$ & $\begin{array}{c}\text { Textural } \\
\text { Empowerment }\end{array}$ \\
\hline \multirow{2}{*}{ N } & Valid & 350 & 350 & 350 & 350 & 350 \\
& Missing & 0 & 0 & 0 & 0 & 0 \\
& Mean & 3.38 & 3.24 & 3.65 & 3.53 & 4.60 \\
& Sum & 1182 & 1133 & 1277 & 1235 & 1610 \\
\hline
\end{tabular}

4.2 Frequency Table

Table 6. Economic empowerment

\begin{tabular}{cccccc}
\hline \multicolumn{5}{c}{ Economic Empowerment } \\
\hline Valid & Frequency & Percent & Valid Percent & Cumulative Percent \\
& Very Low & 37 & 10.6 & 10.6 & 10.6 \\
& Low & 40 & 11.4 & 11.4 & 22.0 \\
& Somewhat & 84 & 24.0 & 24.0 & 46.0 \\
& Much & 132 & 37.7 & 37.7 & 83.7 \\
& Very Much & 57 & 16.3 & 16.3 & \\
& Total & 350 & 350 & 100.0 & \\
\hline
\end{tabular}

Table 7. Social empowerment

\begin{tabular}{cccccc}
\hline \multicolumn{5}{c}{ Social Empowerment } \\
\hline Valid & Frequency & Percent & Valid Percent & Cumulative Percent \\
& Very Low & 45 & 12.9 & 12.9 & 12.9 \\
& Low & 48 & 13.7 & 13.7 & 26.6 \\
& Somewhat & 96 & 27.4 & 27.4 & 54.0 \\
& Much & 101 & 28.9 & 28.9 & 82.9 \\
& Very much & 60 & 17.1 & 17.1 & 100.0 \\
& Total & 350 & 100.0 & 100.0 & \\
\hline
\end{tabular}

Table 8. Management empowerment

\begin{tabular}{cccccc}
\hline \multicolumn{5}{c}{ Management Empowerment } \\
\hline Valid & Frequency & Percent & Valid Percent & Cumulative Percent \\
& Low Low & 25 & 7.1 & 7.1 & 7.1 \\
& Somewhat & 35 & 10.0 & 10.0 & 17.1 \\
& Much & 140 & 18.3 & 18.3 & 35.4 \\
& Very Much & 86 & 24.0 & 40.0 & 75.4 \\
& Total & 350 & 100.0 & 24.6 & 100.0 \\
\hline
\end{tabular}


Table 9. Cultural Empowerment

\begin{tabular}{llcccc}
\hline \multicolumn{5}{c}{ Cultural Empowerment } \\
\hline \multirow{2}{*}{ Valid } & Very Low & 26 & 7.4 & 7.4 & Cumulative Percent \\
& Low & 38 & 10.9 & 10.9 & 7.4 \\
& Somewhat & 85 & 24.3 & 24.3 & 18.3 \\
& Much & 127 & 36.3 & 36.3 & 42.6 \\
& Very Much & 74 & 21.1 & 21.1 & 78.9 \\
& Total & 350 & 100.0 & 100.0 & 100.0 \\
\hline
\end{tabular}

Table 10. Textural empowerment

\begin{tabular}{cccccc}
\hline \multicolumn{5}{c}{ Textural Empowerment } \\
\hline \multirow{2}{*}{ Valid } & Fow & 2 & 0.6 & 0.6 & Cumulative Percent \\
& Somewhat & 11 & 3.1 & 3.1 & 0.6 \\
& Much & 112 & 32.0 & 32.0 & 3.7 \\
& Very Much & 225 & 64.3 & 64.3 & 100.0 \\
& Total & 350 & 100.0 & 100.0 & \\
\hline
\end{tabular}

Using SPSS, doing Chi-square test and calculating Pearson correlation coefficient, the researcher started to examine the hypothesis mentioned below:

If the value of computed number in significant correlation of SPSS is less than the value of Alfa, then the HO which refers to the inexistence of a significant correlation between two variables is rejected and H1 which underlines the existence of a significant correlation, will be approved and finally the hypothesis of the research will be approved. In case of approval of the hypothesis of the research, the value of $\mathrm{R}$ in the Value column in Symmetric Measures can be examined to check the directness or indirectness of the correlation of two variables and if the value of $\mathrm{R}$ is more than zero, the correlation between two variables would be direct and if it is less than zero, then the correlation would be indirect. Considering these explanations and the findings of the study, the $2 \times 2$ matrix of renovation and reformation factors are shortly presented in table 11 .

Table $11.2 \times 2$ matrix of renovation and reformation factors

\begin{tabular}{llllll}
\hline $\begin{array}{l}\text { Empowerment } \\
\text { Renovation }\end{array}$ & $\begin{array}{l}\text { Economic } \\
\text { Empowerment }\end{array}$ & $\begin{array}{l}\text { Management } \\
\text { Empowerment }\end{array}$ & $\begin{array}{l}\text { Social } \\
\text { Empowerment }\end{array}$ & $\begin{array}{l}\text { Cultural } \\
\text { Empowerment }\end{array}$ & $\begin{array}{l}\text { Textural } \\
\text { Empowerment }\end{array}$ \\
\hline Existing & 0.248 & 0.545 & 0.86 & 0.275 & 0.789 \\
Facilities & 0.08 & -0.07 & 0.021 & -0.025 & -0.016 \\
Urban & 0.151 & 0.896 & 0.137 & 0.001 & 0.511 \\
Management & -0.125 & -0.069 & 0.08 & $X$ & -0.126 \\
Participation of & 0.053 & 0.024 & 0.094 & 0.0 & 0.002 \\
Private Section & -0.013 & $\mathrm{X}$ & -0.009 & $\mathrm{X}$ & $\mathrm{X}$ \\
\hline
\end{tabular}

R:

\section{Conclusion}

Empowerment is of main elements of new development paradigm and of main factors of review in a sense that it originally pays more attention to improving the economic and social capacities of the residents in order to participate in the renovation and arrangement of the projects and since the economic strategies didn't work out, 
the word empowerment was expanded to apply in social, cultural and political-management. Regarding the studies done in the present paper, considering the aspects of empowerment and renovation of the texture, the results show that there is a significant correlation between the factors of existing facilities and empowerment indexes and the hypothesis of the research is approved which directly affects the impact of independent variable of existing facilities on social and economic empowerment and indirectly affects the textural, cultural and management empowerment.

Taking other aspects of renovation (management and participation of private section) into account, the relationship between these two factors and the empowerment factors and it can be concluded that there is no significant correlation between cultural empowerment and renovation but there is a significant correlation between renovation and economic, management and textural empowerment and the effects are direct. The relationship between renovation and social empowerment is direct which implies the effect of urban management on creating social capitals in city projects.

Another section of factors of renovation, the participation of private section is in different form which there was no significant correlation between this variable and other variables of management, cultural and textural empowerment regarding the Pearson Coefficient correlation in Table 11, but there is an indirect relationship between social and economic variables. This fact demonstrates that private section participated in city projects if they were profitable for it. The findings show that there is a significant correlation between renovating Zeinabieh and empowering the residents of this district and the hypothesis is approved.

\section{References}

Abers, R. (2001). Learning democratic practice: distributing government resources through popular participation in Porto Alegre, Brazil. The Challenge of Urban Government: Policies and Practices, 130.

Adib Zade, B., Asgari Tafreshi, H., \& Hoseini, A. (2011). Social engineering and the Role of People's Participation in Realizing Renovation of City Old Texture. Architecture and Urbanization Journal, 4, $141-$ 158.

Akbar Pour Sareskanroud, M Pour Ahmad, A., \& Omran Zade, B. (2011). Evaluation of People's Participation in Renovation and Reconstruction of Old Textures, Case Study: Sirous Neighborhood of Teheran. Geography and Planning Joournal, 36.

Andalib, A. (2007). New Strategy toward Managing Renovation of Old Texture of Teheran. Renovation Organization of Teheran. Teheran: Rey Publication., 12.

Asadian, F., \& Sayahi, Z. (2011). The Role of People's Participation Pattern in Renovation and Reformation of Old Texture Using Geographical System of Data. Environment Preparation Journal, 12, 139-163.

Bouchani, M. (2004). Reconstruction and Renovation of Old Urban Texture. Municipalities Journal, 6(62), 42-58.

Ezhdari Tashriq, A. (2004). The Principles and Criteria of Renovation and Reformation of Old Texture. Elmo Sanat University of Iran.

Falamaki, M. (2004). Reviewing the Experiences of Urban Renovation from Venice to Shiraz. Teheran: Faza Publication, 159.

Habibi, M., \& Maghsudi, M. (2007). Urban Renovation: Definition, Theories, Experiences, Regulations and Global Resolution, Methods and Urban Measures. Tehran: Teheran University, 5.

Khademolhoseini, A., \& Arefi Pour, S. (2012). Participatory Urbanization and People's Place in Urban Planning. Geographical Perspective, 7(19), 123-108.

Movahed, A., Firouzi, M., Zare-ee, R., \& Zafari, M. (2013). The Role of People-Oriented Organizations for Participating in Renovating Old Texture. The Journal of Geography Associations of Iran, 11(36), 79-98.

Plato. (1969). The Republic. Book Publication Institute, 25-46.

Rahnama, R. (1996). Renovating the Old Texture and Developing Tourism.

Ziari, K., Nik Pey, \& Hoseini, A. (2013). Measuring the Citizens' Participation in Urban Management according to Urban Ruling. Housing and Village Environment, 141, 69-86.

\section{Copyrights}

Copyright for this article is retained by the author(s), with first publication rights granted to the journal.

This is an open-access article distributed under the terms and conditions of the Creative Commons Attribution license (http://creativecommons.org/licenses/by/3.0/). 